\title{
SMAW Process in Terms of the Amount of Oxygen
}

\author{
Węgrzyn Tomasz \\ Silesian University of Technology, Faculty of Transport \\ Poland
}

\section{Introduction}

It has long been known criterion for welding due to the hydrogen content in the steel weld. The presence of hydrogen in the welds is translated into deterioration of plastic properties and strength of welded joints. Hydrogen amount has an adverse effect on safety of structures. Hydrogen in welded joints (e.g. of the structure of the vehicle) is an unfavourable element. There is a very similar negative role of nitrogen effect in steel WMD (weld metal deposit), and classification of welding methods in terms of WMD was done in 2000. There is not the same role of oxygen in weld metal deposits. Some authors are convinced, that oxygen could be treated as a negative elements, some others suggest that also very small amount of oxygen in weld is not beneficial. It is connected with austenite transformation info acicular ferrite. That phase has better condition to be formed when there are oxide inclusions inside the austenite grains. Because of that oxygen amount in steel should be better known and correctly classified similarly to the amount of hydrogen and nitrogen in welds.

Proposal of the welding processes classification of low-carbon and low-alloy steel in terms of the amount of oxygen was firstly suggested on ISOPE Conference in Brest in 1999. Since then, a new research has confirmed the valid of this concept. Nevertheless that criterion is still not very popular. Welding with coated electrodes (especially basic, rutile, acid electrodes) is very representative method to analyse that problem. The amount of oxygen in WMD has main influence on the acicular ferrite percentage in it. Metallographic structures, impact toughness and fractograph analysis of weld metal deposit with varied amount of oxygen were carried out (by putting attention to non-metallic inclusions presence in deposit) to analyse mechanical properties of WMD in terms of oxygen content. Also N-S curves were measured for typical deposits with varied amount of oxygen in WMD. Additional inclusions observation and measurements were prepared using a scanning electron microscope equipped with an energy-dispersive $\mathrm{X}$-ray spectrometer.

\section{Oxygen effect in welds}

Effect of oxygen in weld is not the same like in steel. Amount of oxygen in WMD is normally ten times higher in comparison with steel (normally in range 300-1000 ppm O). It was observed that oxygen amount and further oxide inclusions in steel metal weld deposit 
have main influence on the transformation austenite $\rightarrow$ acicular ferrite (AF). The quality, quantity, type and size of oxide inclusions determines the formation of acicular ferrite. Thus the toughness and fatigue properties of the weld metal deposits are affected by the amount of oxygen and the amount of acicular ferrite in the metal weld deposits. The toughness of the WMD is also affected by morphology and density of inclusions. This is the reason, why the amount of oxygen could be treated as the important factor on metallographic structures and impact properties of weld metal deposit. In metallurgy of steel, it is treated that the lowest amount of oxygen gives good toughness properties of steel. The amount of oxygen in weld metal deposit depends mainly on filler materials and methods of welding.

\subsection{Oxygen effect in covered electrode deposits}

Shielded Metal-Arc Welding (SMAW) process was chosen to assess the effect of oxygen on mechanical properties of WMD. The electrodes contained coatings, constant or variable proportions of standard components in powder form. The principal composition was modified by separate additions of oxidiser $\left(\mathrm{Fe}_{3} \mathrm{O}_{4}\right)$ and deoxidisers $(\mathrm{FeTi}, \mathrm{FeSi}$ and $\mathrm{Al}$ in powder form) in electrode coatings. The principal diameter of the electrodes was $4 \mathrm{~mm}$. The standard current was $180 \mathrm{~A}$, and the arc voltage was $22 \mathrm{~V}$. As a result after welding, the amount of oxygen in low-carbon and low-alloy steel metal weld deposits ranged between 200 and $1100 \mathrm{ppm}$.

A typical low alloy low carbon weld metal deposits after SMAW process had the following chemical composition (table 1):

\begin{tabular}{|c|c|}
\hline Chemical element in WMD & Amount of element in WMD \\
\hline $\mathrm{C}$ & bellow $0,06 \%$ \\
\hline $\mathrm{Mn}$ & up to $1,4 \%$ \\
\hline $\mathrm{Si}$ & up to $0,4 \%$ \\
\hline $\mathrm{Al}$ & up to $0,02 \%$ \\
\hline $\mathrm{Ti}$ & up to $0,02 \%$ \\
\hline $\mathrm{P}$ & max $0,013 \%$ \\
\hline $\mathrm{S}$ & max. $0,013 \%$ \\
\hline $\mathrm{N}$ & max. $80 \mathrm{ppm}$ \\
\hline $\mathrm{O}$ & 200 to $1100 \mathrm{ppm}$ \\
\hline
\end{tabular}

Table 1. Chemical composition of WMD

For each the following deposits a chemical analysis was carried out. It was shown that in basic, rutile and acid electrode deposits were gettable various oxygen contents (table 2).

\begin{tabular}{|c|c|}
\hline Covered electrodes & $\begin{array}{c}\text { Oxygen amount in WMD, } \\
\text { ppm }\end{array}$ \\
\hline acid & in range $800-1100$ \\
\hline rutile & in range $600-800$ \\
\hline basic & in range $200-500$ \\
\hline
\end{tabular}

Table 2. Oxygen amount in various covered electrodes

For each the following deposits (basic, acid, rutile) micrograph tests, impact toughness, fatigue and fractograph tests were precisely carried out. 


\subsection{WMD properties in terms of oxygen amount}

After chemical analysis for each the following deposits micrograph tests, and Charpy Vnotch impact toughness test were firstly taken. The main Charpy tests were done mainly at $+20^{\circ} \mathrm{C}$ using 5 specimens from each weld metal. Charpy V-notch impact toughness tests of the selected weld metal at lower temperatures were also done with 5 specimens. On the bases of the results shown in figure 1, the role of oxygen in the SMAW process was analysed.

\section{$\mathrm{KV}, \mathbf{J}$}

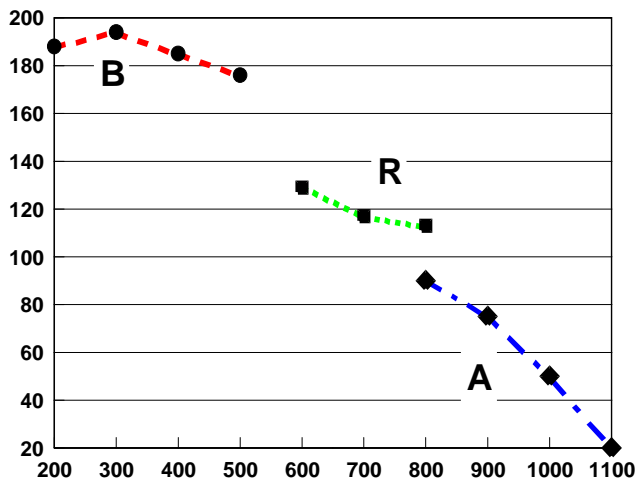

Oxygen in weld metal deposit, ppm

Fig. 1. Impact toughness $\left(\right.$ at $\left.20^{\circ} \mathrm{C}\right)$ of deposits with variable amount of oxygen. Deposits were experimented by: acid electrodes (EA), rutile electrodes (ER) and basic electrodes (EB)

In figure 1 it is well shown that oxygen has an influence on impact toughness properties of metal weld deposit. For each the following deposits (basic, acid, rutile) micrograph tests were carried out. Micrograph structure are presented in figure 2, 3, 4 .

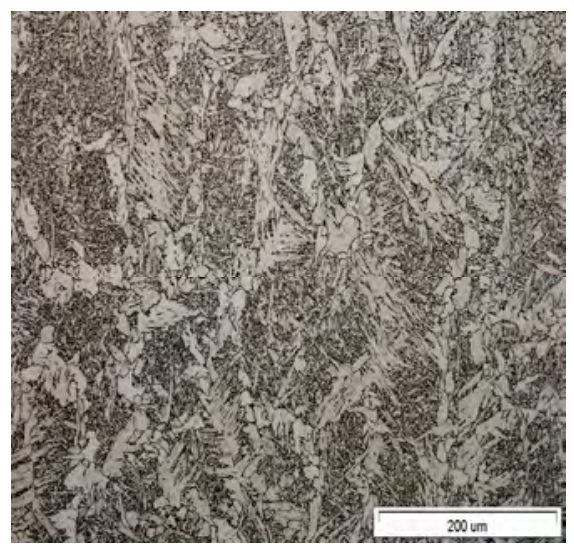

Fig. 2. Typical micrograph structure of acid electrode WMD 


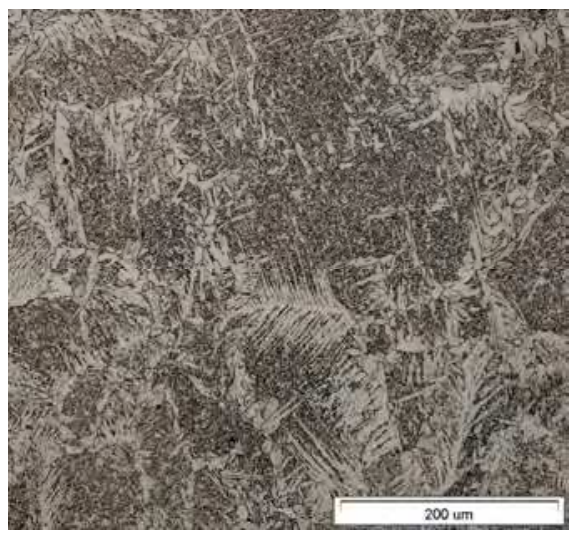

Fig. 3. Typical micrograph structure of rutile electrode WMD

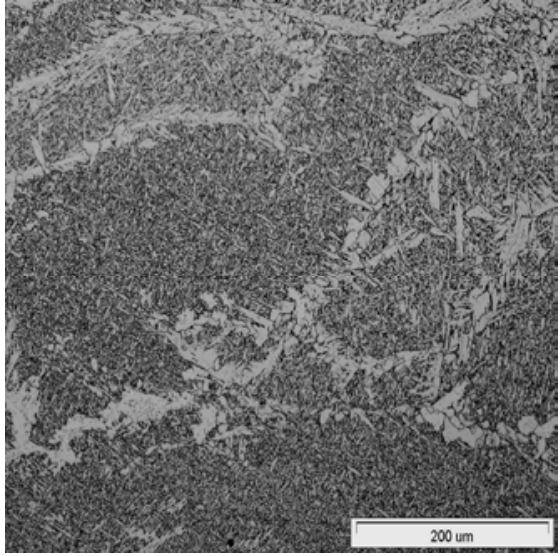

Fig. 4. Typical micrograph structure of basic electrode WMD

Analyzing figures 2, 3, 4 it was easy to deduce that there is varied amount of acicular ferrite, the most beneficial phase in deposits. The difference between amount of AF in welds is shown below in table 3 .

\begin{tabular}{|c|c|}
\hline Covered electrodes & Acicular ferrite in WMD, $\%$ \\
\hline acid & in range $25-33$ \\
\hline rutile & in range 36-44 \\
\hline basic & in range 52-65 \\
\hline
\end{tabular}

Table 2. Oxygen amount in various covered electrodes

Acid electrode deposits were not analysed precisely in that chapter because of unfavourable structure and low impact toughness properties. Fractograph tests were chosen understand more the difference between structure and impact toughness of deposits with various amount of oxygen. Fractograph tests indicates more that amount of acicular ferrite in WMD is connected with the size of inclusions (and their chemical composition), figure 5, 6 . 


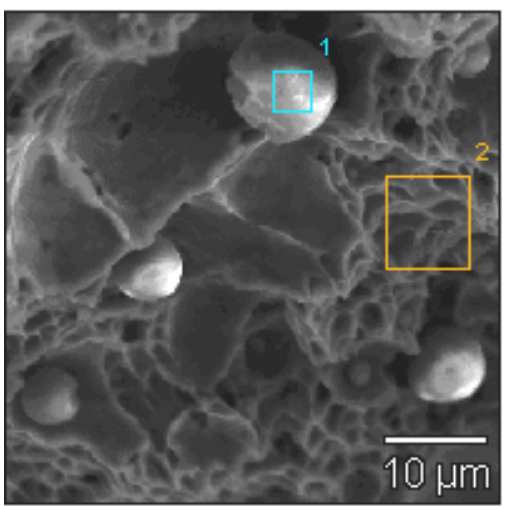

Fig. 5. Very big inclusions of rutile electrode WMD

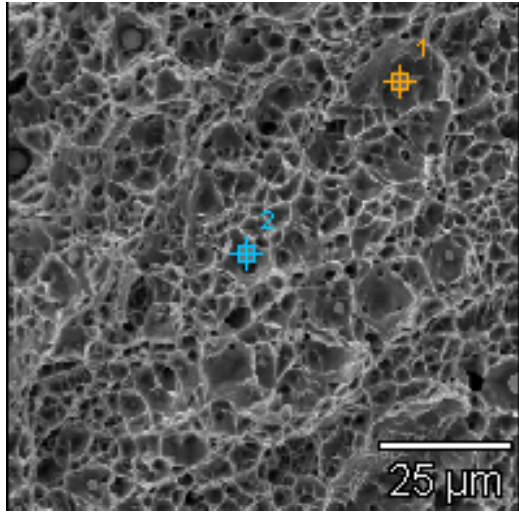

Fig. 6. Typical inclusions of basic electrode WMD

It is possible to observe, that there is not the same size of inclusions in basic and rutile deposits. Size distribution is shown in figures $7,8,9$.

Only fractography of rutile and basic electrodes were precisely tested. The quality, quantity, type and size of inclusions determines the formation of acicular ferrite. It is possible to deduce that inclusions are heterogeneous nature and that the following oxides $\mathrm{TiO}_{2}, \mathrm{TiO}$, $\mathrm{FeO}, \mathrm{SiO}_{2}, \mathrm{MnO}, \mathrm{CaO}, \mathrm{MgO}, \mathrm{MnAl}_{2} \mathrm{O}_{4}, \mathrm{Al}_{2} \mathrm{O}_{3}$ are dominant. Also the size of inclusions could have an influence on forming acicular ferrite and thereby resulting in obtaining better impact toughness properties. Thus the toughness of the weld metal deposits is affected by the amount of oxygen and the amount of acicular ferrite in the metal weld deposits. Basic electrode deposits had about $50-60 \%$ of acicular ferrite, rutile electrode deposits had $40-50 \%$ of acicular ferrite, and finally acid electrode deposits had less than $40 \%$ of AF. It could be easy to understand relation between impact toughness and AF content in WMD (figure 1).

Last part of that chapter was to compare N-S curves (figures 12,13) of typical deposits of basic and rutile electrodes giving various amount of oxygen in welds after process. Fatigue tests were generated for two deposits analysed in figures 10 and 11 with low amount of 
oxygen on the level of $345 \mathrm{ppm}$ (typical for basic electrodes), and $650 \mathrm{ppm}$ (typical for rutile electrodes).

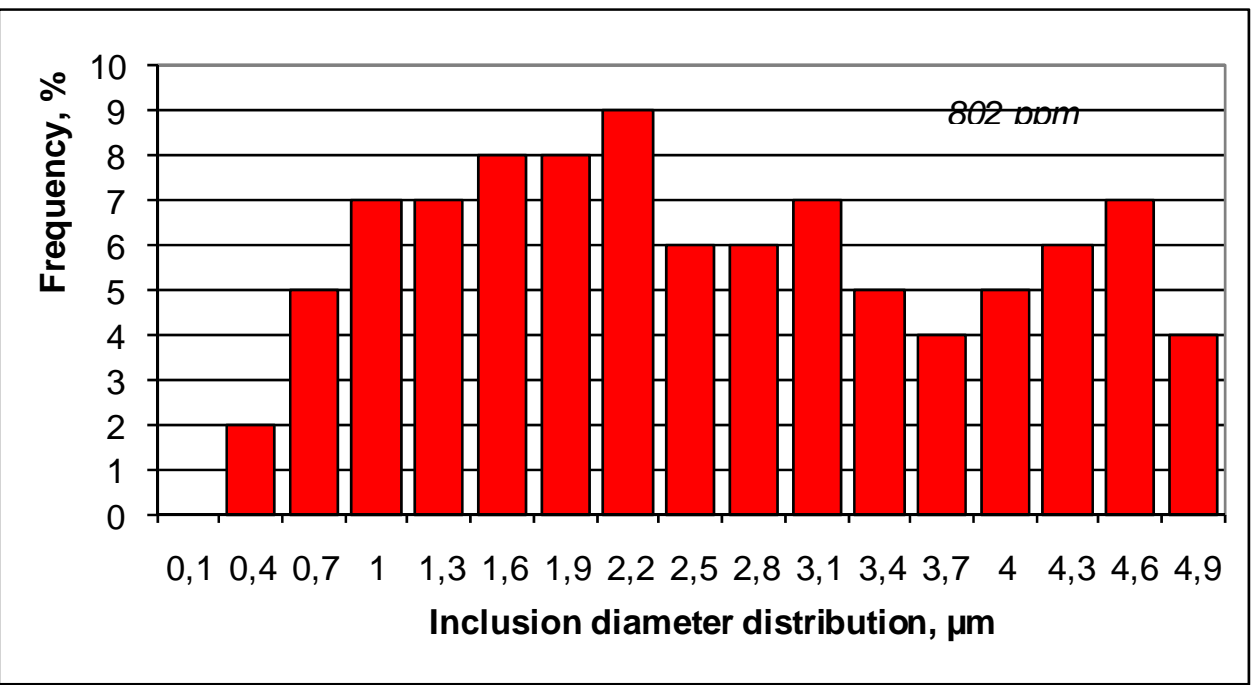

Fig. 7. Typical inclusions distribution of acid electrode WMD

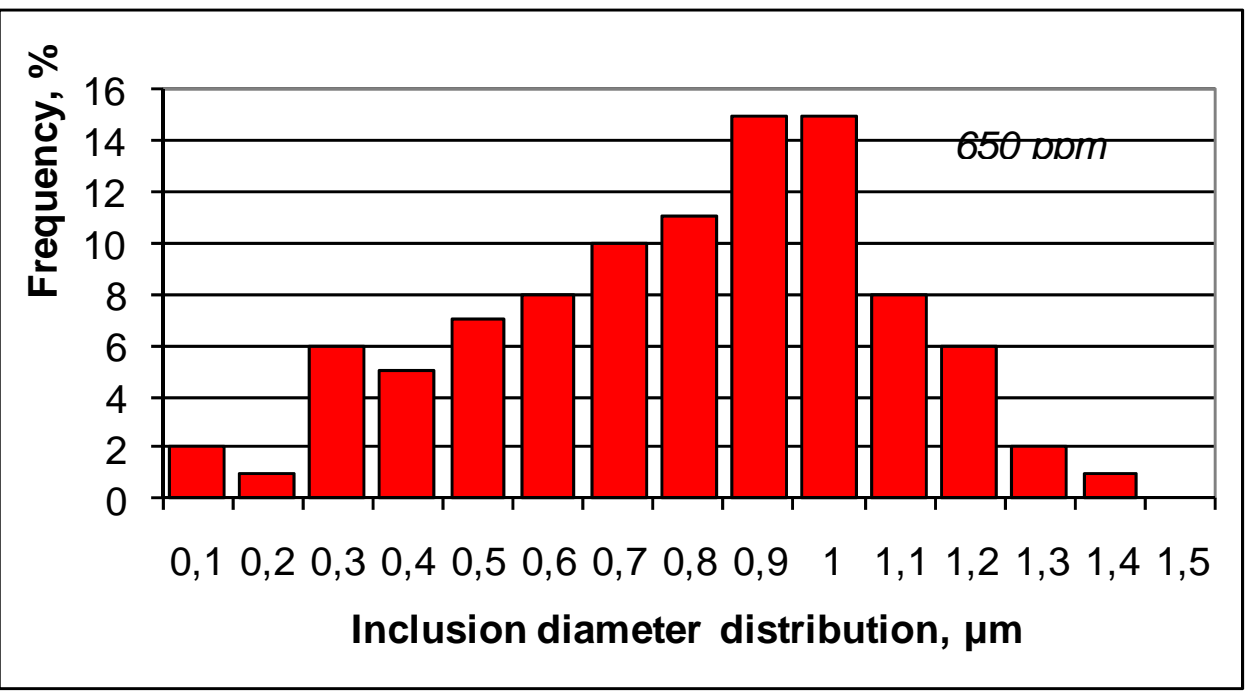

Fig. 8. Typical inclusions distribution of rutile electrode WMD 


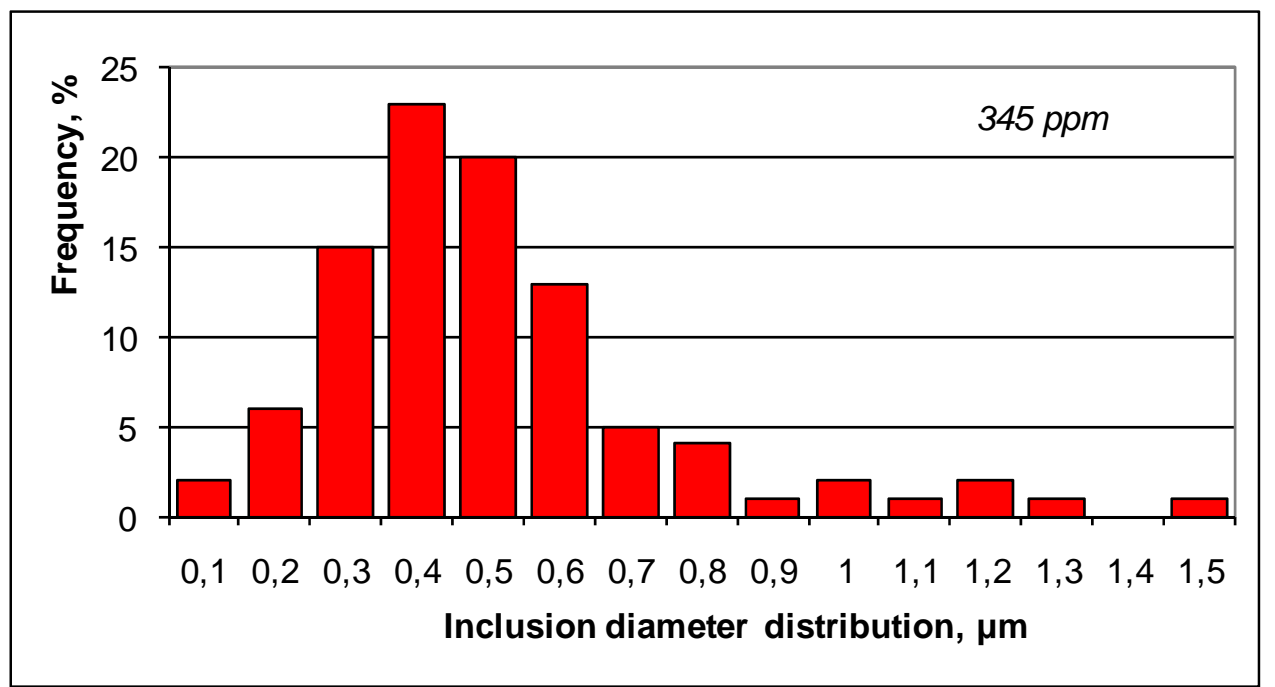

Fig. 9. Typical inclusions distribution of basic electrode WMD

Also chemical composition of inclusions was carefully measured (figures 10, 11).

\section{Full scale counts: 549}

\section{Stopiwo 32_pt1}

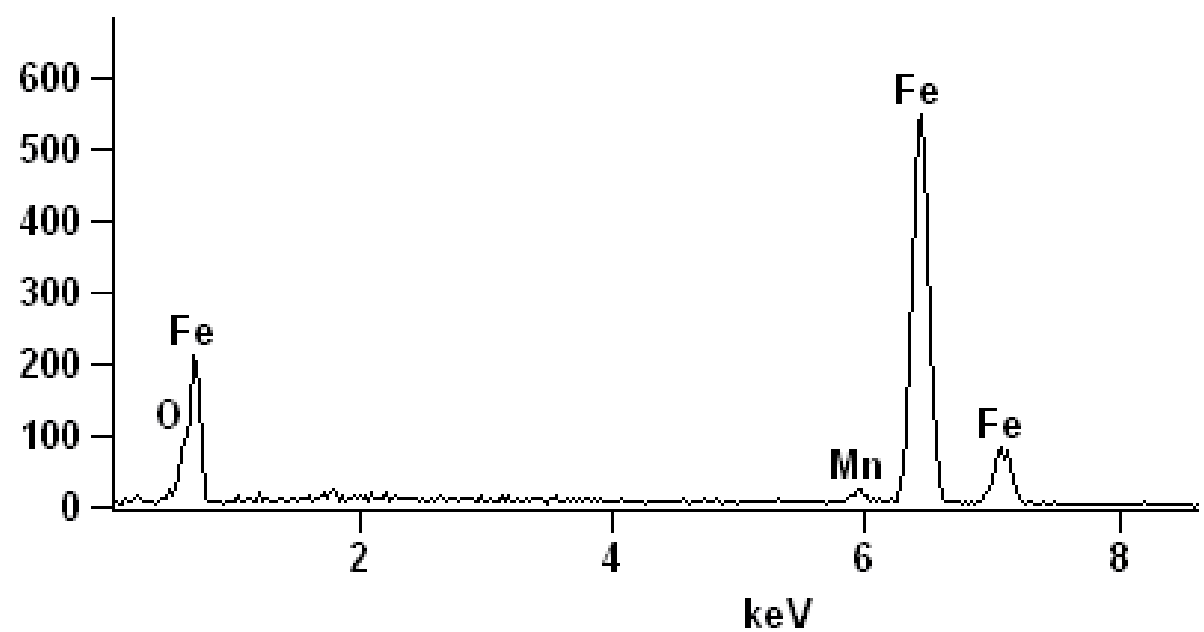

Fig. 10. Elements of oxide inclusions in rutile WMD 
Full scale counts: 7091

Stopiwo 25_pt1

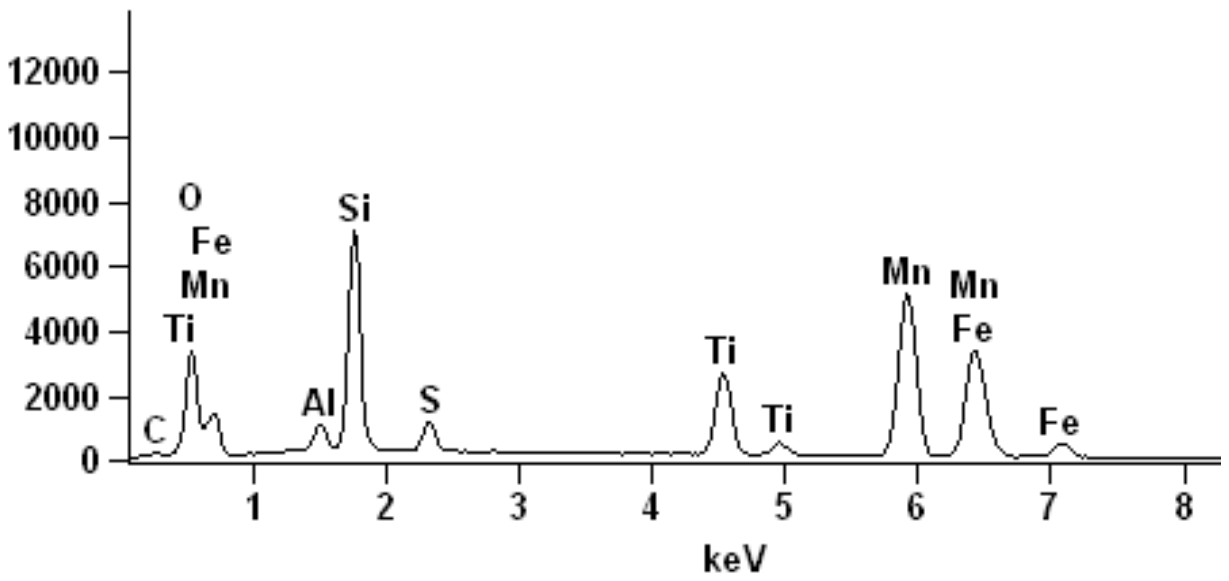

Fig. 11. Elements of oxide inclusions in basic WMD

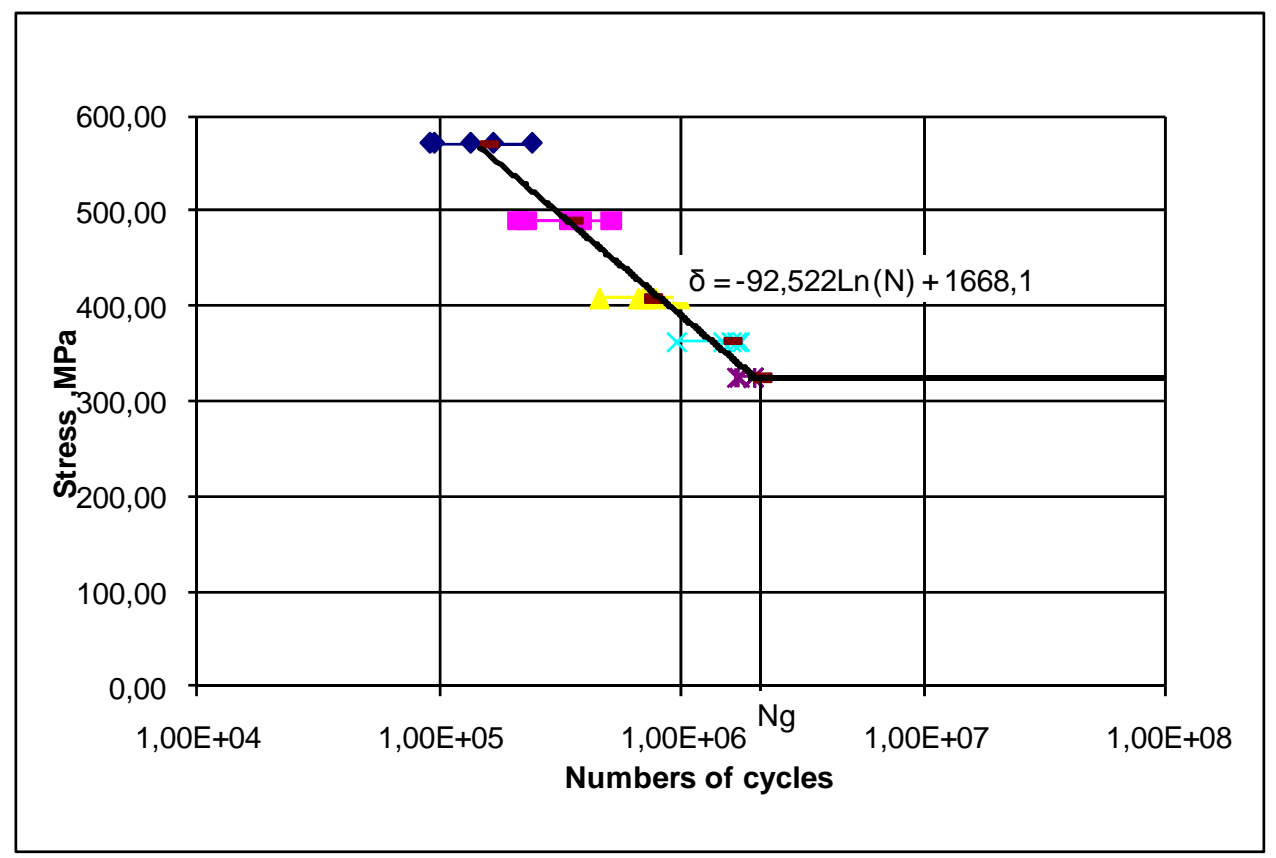

Fig. 12. S-N Fatigue properties for WMD with 345 ppm O

Looking for the S-N curve for the deposit to make an estimate of its fatigue life it easy to deduce, that low amount of $\mathrm{O}$ could be treated as beneficial (comparison with WMD having $650 \mathrm{ppm})$. 


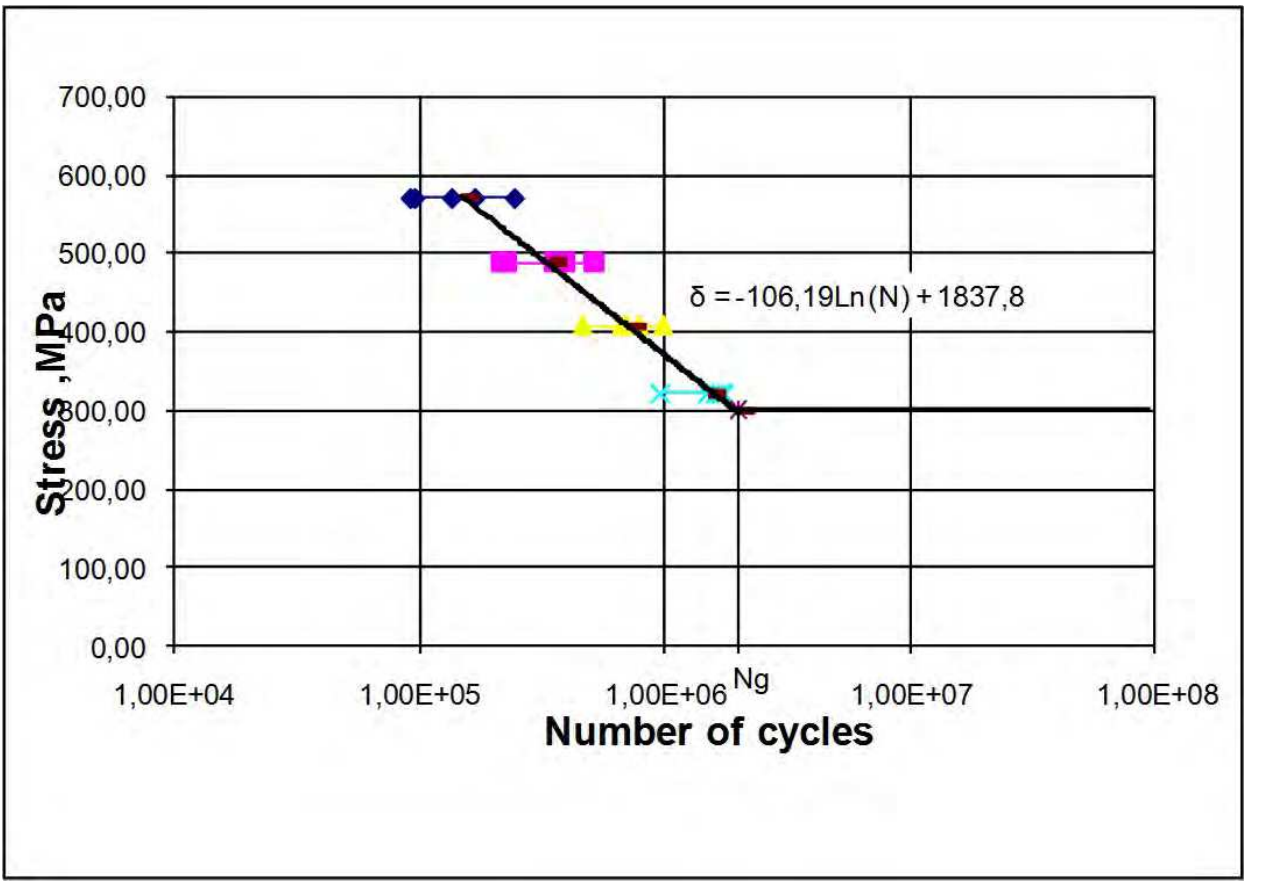

Fig. 13. S-N Fatigue properties for WMD with $650 \mathrm{ppm} \mathrm{O}$

I was able to compare the fatigue values for deposits having various amount of oxygen. Also in this case deposits having lower amount of oxygen could be treated as more beneficial.

Examination of the influence of amounts of oxygen on alloy steel weld metal deposit allows to prove that classification of arc welding processes in terms of the amount of oxygen in weld metal deposits is very important.

Proposal of the classification for electrodes and SMAW welding processes:

- low-oxygen electrodes/process (amount of oxygen in metal weld deposit is in range 250 $\div 450$ ppm),

- medium-oxygen electrodes/process (amount of oxygen in metal weld deposit is in range $450 \div 650 \mathrm{ppm}$ ),

- high-oxygen electrodes/process (amount of oxygen in metal weld deposit is greater than $650 \mathrm{ppm})$.

\section{Main elements in steel WMD}

Apart from oxygen it is important to control amount other important elements in weld metal deposit: especially $\mathrm{Mn}, \mathrm{Ni}, \mathrm{Mo}, \mathrm{Cr}, \mathrm{V})$. On the study done in chapter 2 it is easy to deduce that amount of oxygen in metal weld deposit should be always in range $250 \div 450$ ppm. Nickel, molybdenum, chromium, vanadium are also regarded as the main factors 
effecting on mechanical properties and metallographic structure of low alloy welds. However there is different influence of all those elements on mechanical properties of welds in comparison with oxygen. The influence of the variable amounts of nickel, molybdenum, chromium, vanadium on impact properties of low alloy metal weld deposit was carefully presented below. Chromium, vanadium, and especially nitrogen are regarded rather as the negative element on impact toughness properties of low alloy basic electrode steel welds in sub zero temperature, meanwhile nickel and molybdenum have the positive influence on impact properties. Authors of the main publications present that the content of nitrogen in low alloy weld metal deposit should not be greater than $80 \mathrm{ppm}$, and that nickel content should not exceed 3\%. It is observed that nickel (from $1 \%$ to $2 \%$ ) in metal weld deposit gives good impact toughness properties of welds. The lowest amount of nitrogen in all weld metal gives the best impact results of metal weld deposit. It was suggested that nitrogen has similar role as carbon in the ferrite. The amount of nitrogen in low-carbon and low-alloy steel is limited, but in high alloy steel welds the amount of nitrogen could be sometimes even augmented to obtain optimal mechanical properties of welds. After the welding process using basic covered electrodes (low oxygen process) there were compered metal weld deposits with the variable amounts of tested elements (Mn, Cr, Mo, V, Ni) in it. After that the chemical analysis, micrograph tests, and Charpy notch impact toughness tests of the deposited metal were presented. The Charpy tests were done mainly at $+20^{\circ} \mathrm{C}$ and $-40^{\circ} \mathrm{C}$ with 5 specimens having been tested from each weld metal. The impact toughness results are given in figures 14-19.

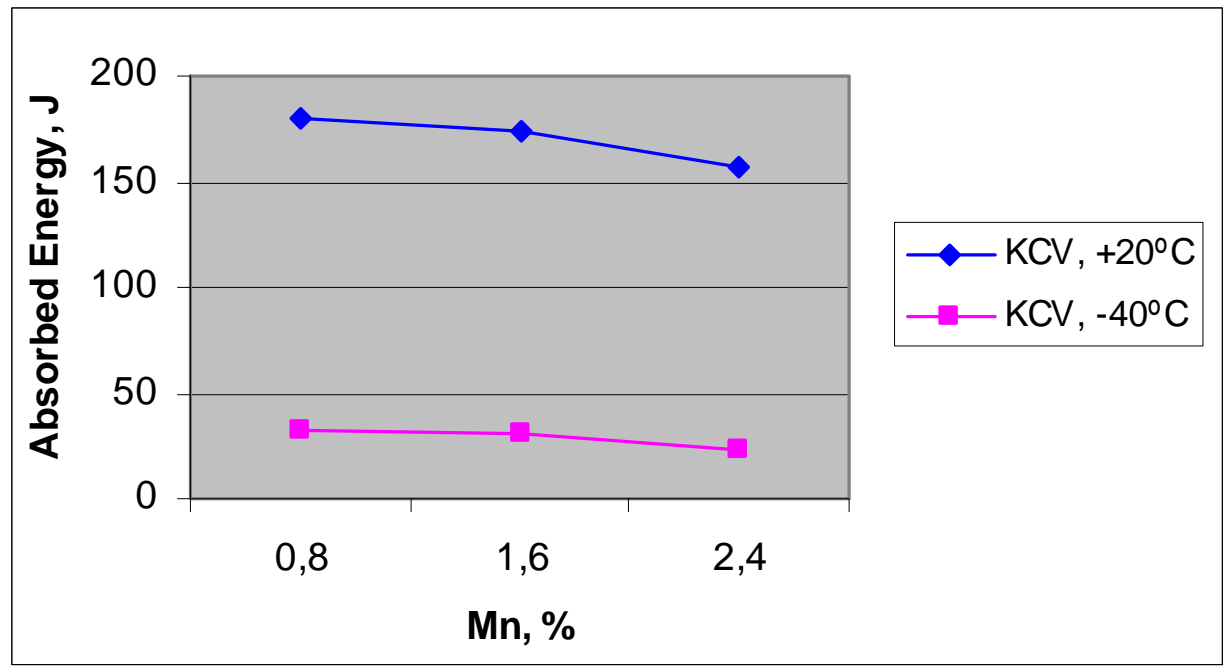

Fig. 14. Relations between the amount of Mn in MWD and the impact toughness of MWD (low-oxygen welding process)

Analysing figure 14 it is possible to deduce that impact toughness of metal weld deposit is not strongly affected by the amount of manganese. Absorbed energy in terms of the amount of vanadium in metal weld deposit is shown in figure 15. 


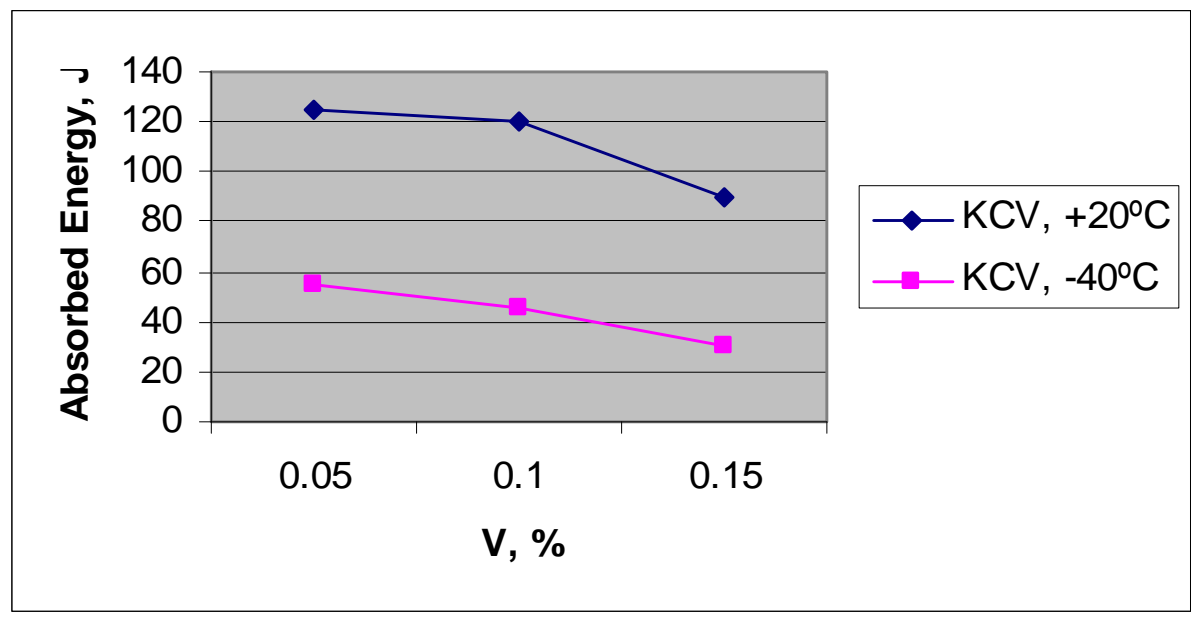

Fig. 15. Relations between the amount of $\mathrm{V}$ in MWD and the impact toughness of MWD (low-oxygen welding process)

Analysing figure 15 it is possible to deduce that impact toughness of metal weld deposit is much more affected by the amount of vanadium than manganese. Absorbed energy in terms of the amount of chromium in metal weld deposit is shown in figure 16.

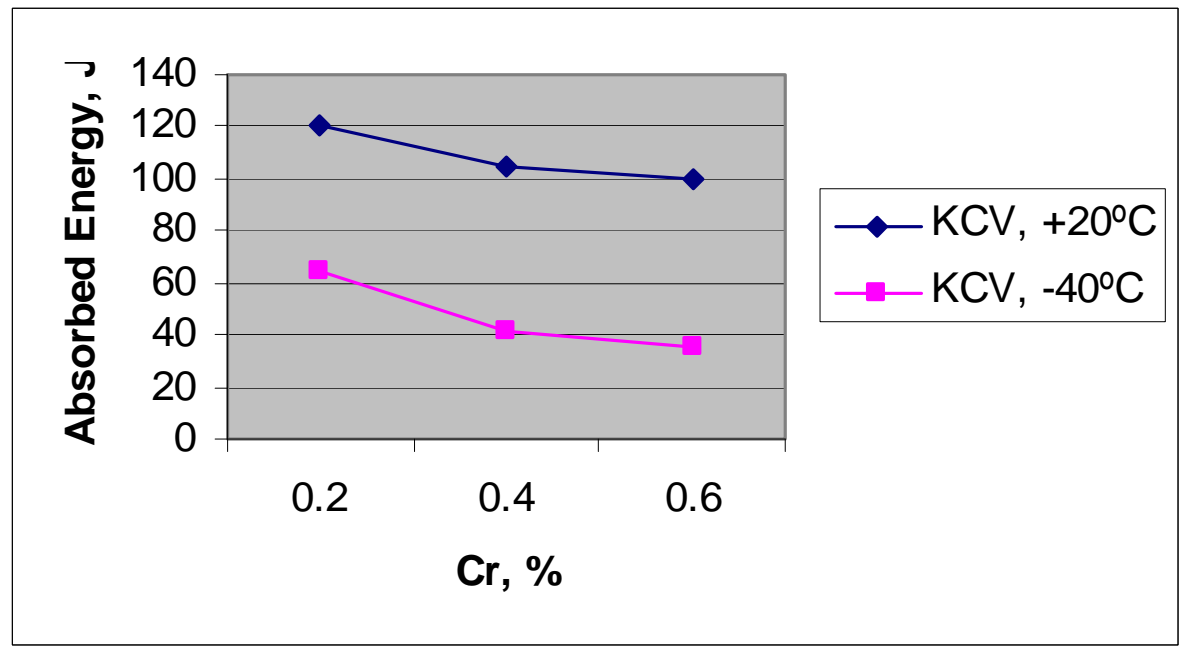

Fig. 16. Relations between the amount of $\mathrm{Cr}$ in MWD and the impact toughness of MWD (low-oxygen welding process)

Analysing figure 16 it is possible to observe that impact toughness of weld metal deposit is also much more affected by the amount of chromium than manganese. Absorbed energy in terms of the amount of nickel in metal weld deposit is shown in figure 17. 


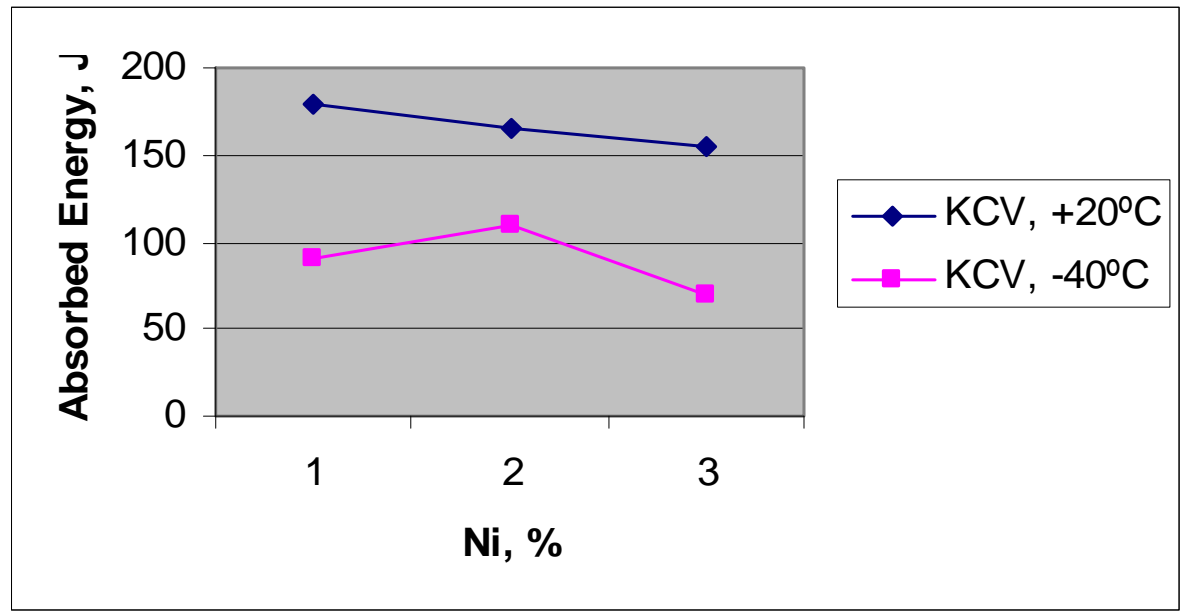

Fig. 17. Relations between the amount of $\mathrm{Ni}$ in MWD and the impact toughness of MWD (low-oxygen welding process)

Analysing figure 17 it is possible to deduce that impact toughness of metal weld deposit is very positively affected by the amount of nickel. Absorbed energy in terms of the amount of molybdenum in metal weld deposit is shown in figure 18.

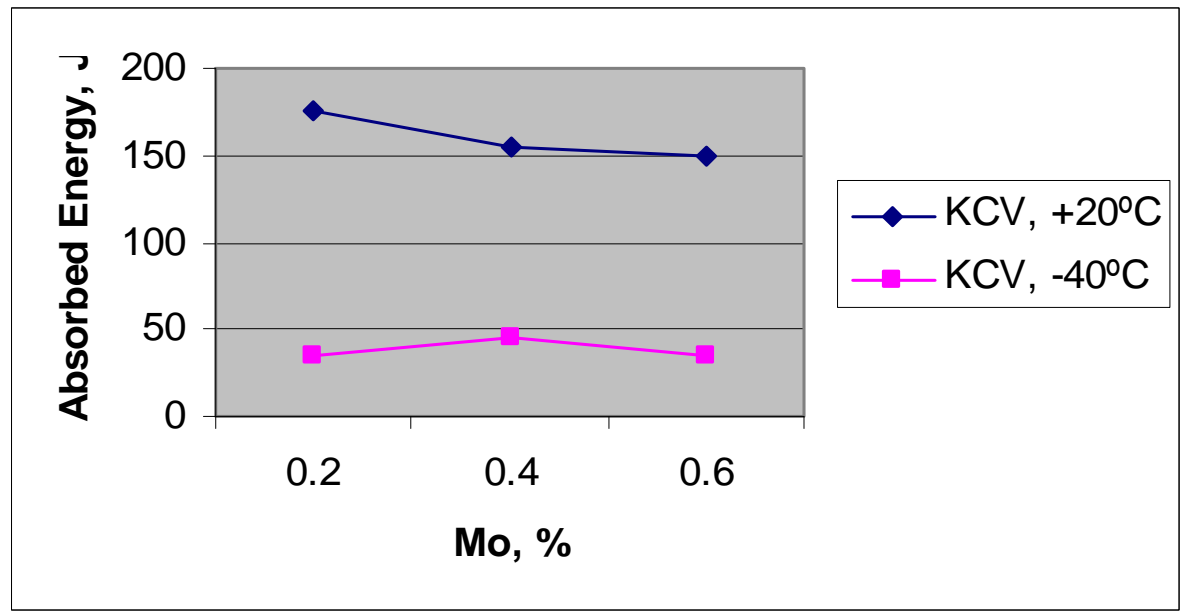

Fig. 18. Relations between the amount of Mo in MWD and the impact toughness of MWD (low-oxygen welding process)

Analysing figure 18 it is possible to observe that impact toughness of weld metal deposit is also very positively affected by the amount of molybdenum. The microstructure and fracture surface of metal weld deposit having various amount of nickel and vanadium was also done. Acicular ferrite and MAC phases (self-tempered martensite, upper and lower 
bainite, rest austenite, carbides) were analysed and counted for each weld metal deposit. Amount of AF and MAC were on the similar level in deposits with $\mathrm{Ni}$ and Mo, also for deposits with $\mathrm{V}$ and $\mathrm{Cr}$ there were observed rather similar structure. Results of deposits with various structure are shown in figures 19, 20.

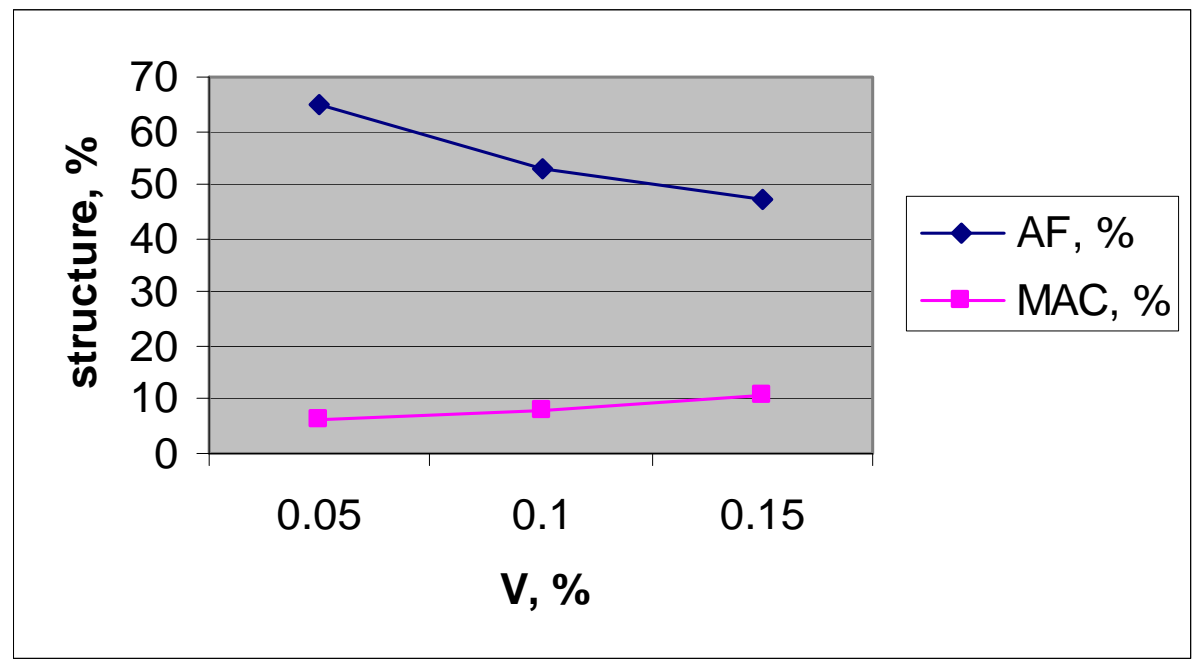

Fig. 19. Metallographic structure with V in MWD (low-oxygen welding process)

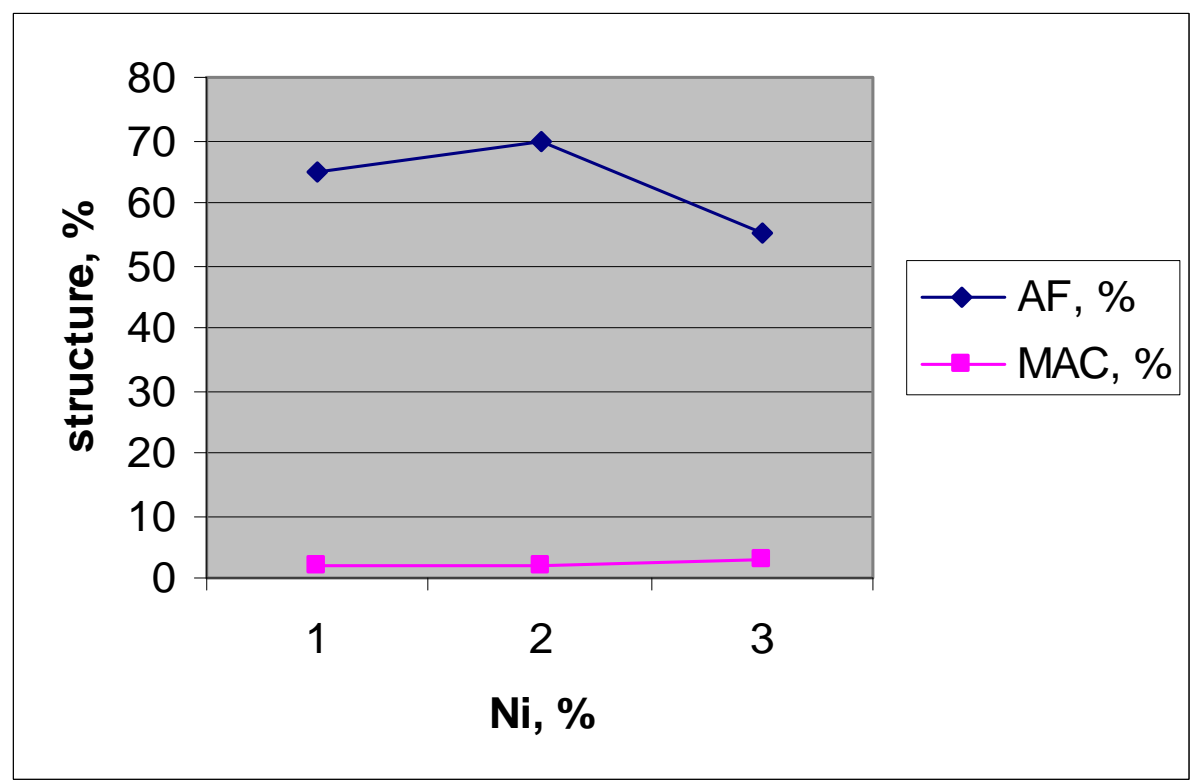

Fig. 20. Metallographic structure with Ni in MWD (low-oxygen welding process) 
It was easy to deduce that nickel and molybdenum have positive influence on the structure. That relation was firstly observed in impact toughness tests. Nickel and molybdenum could be treated as the positive elements influencing impact toughness and structure of MWD because of higher amount of acicular ferrite and lower amount of MAC. Chromium and vanadium could be treated as the negative elements influencing impact toughness and structure of MWD. Manganese could be treated as a neutral element influencing impact toughness of MWD. Additional fracture surface observation was done using a scanning electron microscope. The fracture of weld metal deposit having $1.1 \% \mathrm{Ni}$ is presented in figure 21, and the fracture of metal weld deposit having $0.6 \% \mathrm{Cr}$ is presented in figure 22 .

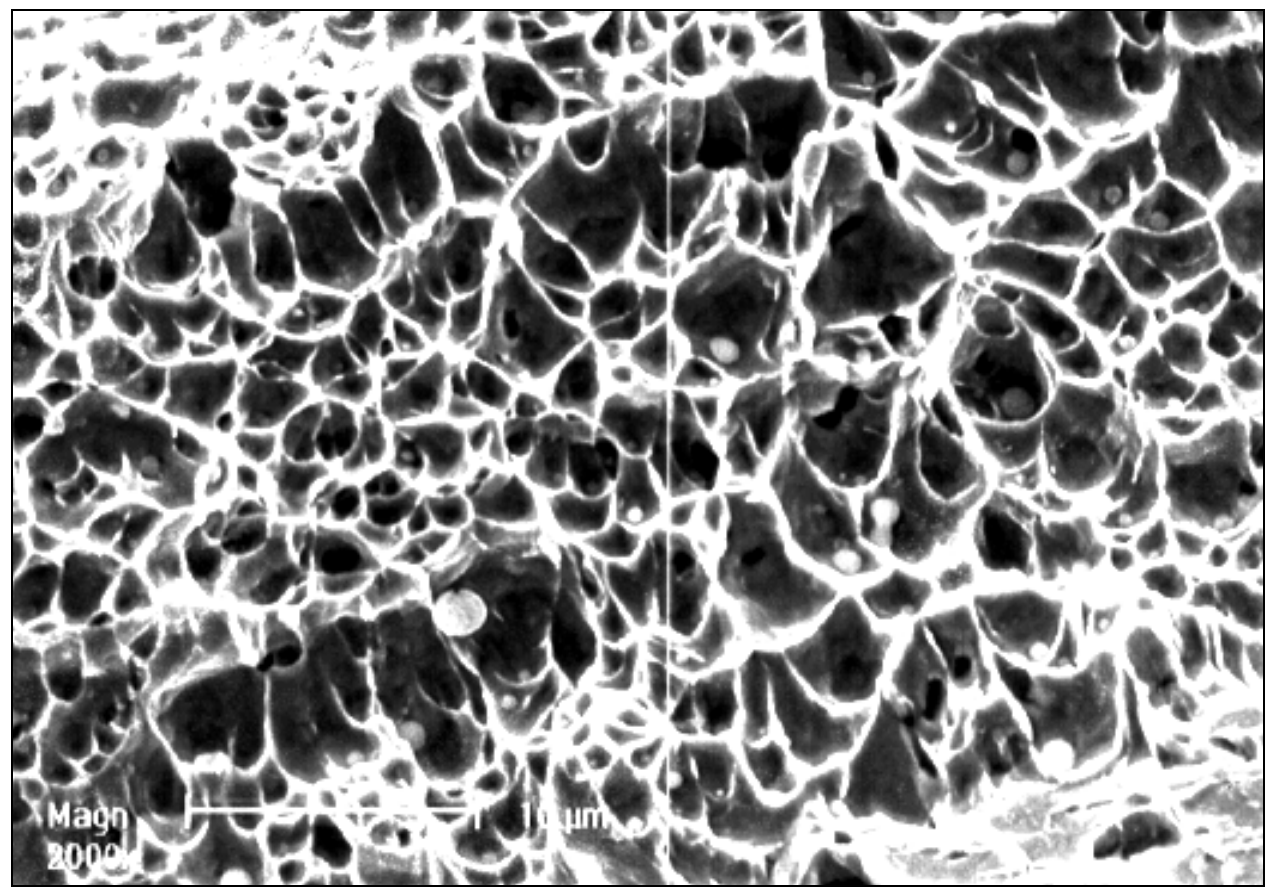

Fig. 21. Fracture surface of metal weld deposit, magnification 2000× (low-oxygen welding process)

The surface is ductile, because of the beneficial influence of nickel on the deposit structure. After microscope observations it was determined that the amount of nickel (or molybdenum) has a great influence on the character of fracture surface. The surface was ductile also for MWD having Mo in it. The character of fracture surface changed from ductile to much brittle in terms of the increscent of the amount of vanadium (or chromium). The typical fracture of metal weld deposit having $0.6 \% \mathrm{Cr}$ is presented in figure 12 .

The surface is less ductile, because of the higher amount of chromium in deposit. The surface was brittle also for MWD having V in it. After microscope observations it was determined that the amount of chromium (or vanadium) has also a great influence on the character of fracture surface. The character of fracture surface changed from ductile to much 
brittle in terms of the increscent of the amount of chromium. Nickel and molybdenum are positive elements in low alloy metal weld deposits. Chromium and vanadium cannot be treated as positive elements in low alloy metal weld deposits. Manganese could be rather treated as a neutral element influencing impact toughness properties. Nevertheless it is important to remember, that all investigation about $\mathrm{Ni}, \mathrm{Mn}, \mathrm{Cr}, \mathrm{V}$, Mo was done always for log-oxygen welding methods.

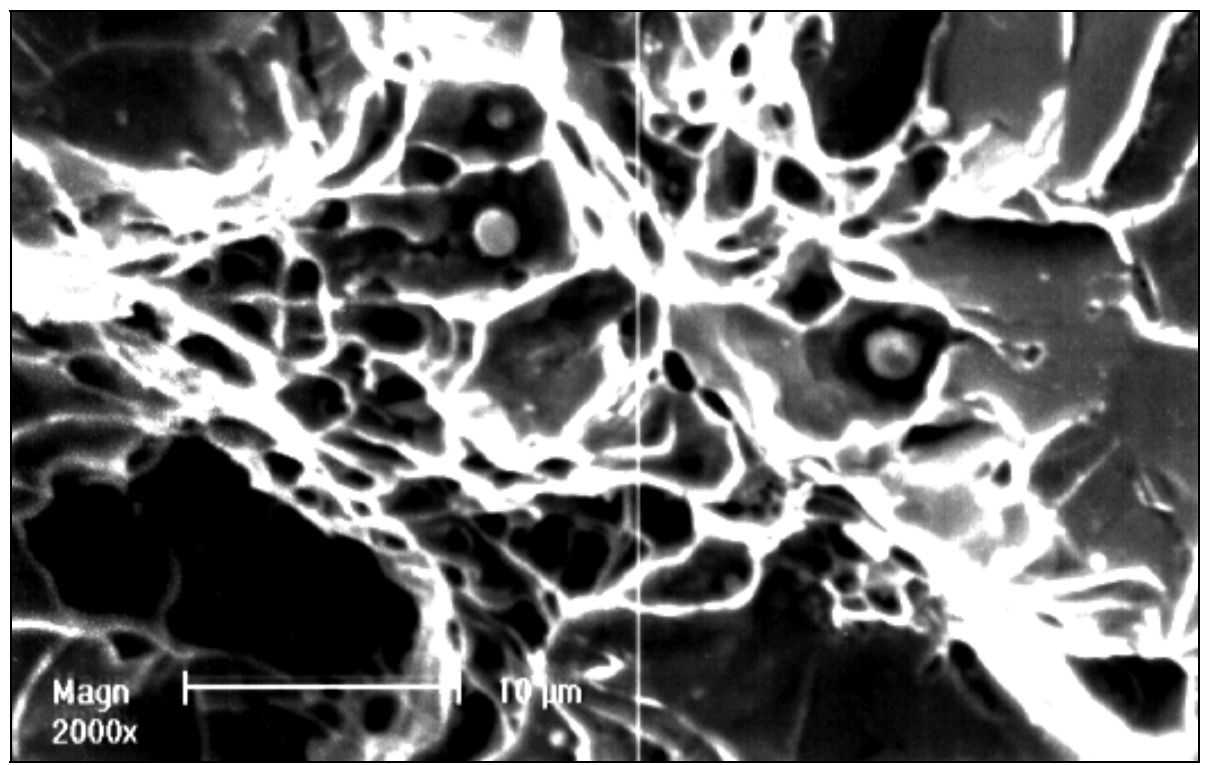

Fig. 22. Fracture surface of metal weld deposit, magnification $2000 \times$ (low-oxygen welding process)

\section{Conclusion}

Actual examination of the influence of amount of oxygen on alloy steel weld metal deposit allows to suggest that classification of filler materials and arc welding processes in terms of the amount of oxygen in WMD was correctly proposed in $1999 \mathrm{y}$. It is still important to remind a proposal of the classification for electrodes and SMAW processes:

- low-oxygen electrodes/process

(amount of oxygen in metal weld deposit is in range $250 \div 450 \mathrm{ppm}$ )

- medium-oxygen electrodes/process

(amount of oxygen in metal weld deposit is in range $450 \div 650 \mathrm{ppm}$ )

- $\quad$ high-oxygen electrodes/process

(amount of oxygen in metal weld deposit is greater than $650 \mathrm{ppm}$ )

\section{Acknowledgment}

Purpose: Main goal of this chapter is to remind proposals for welding processes classification in terms of oxygen in WMD, and confirmation of that concept after further 12 
years of new research and results. Welds were obtained with various oxygen content. There were investigated properties of WMD, especially metallographic structure, toughness and fatigue strength of welds with various oxygen amount. The connection between the properties of welds with the content of oxygen in WMD were carried out.

Findings: Demonstrated that oxygen content in WMD has an important influence on metallographic structure, especially on the percentage of acicular ferrite in weld. The preferred structure improves the mechanical properties of welded joints. The research results indicate that it should be limited oxygen content in steel welds. Subsequent researchers could find more precisely the most beneficial oxygen amount in the welds in terms of the amount of acicular ferrite in welds.

Practical implications: To obtain welds with the best properties should be chosen suggested low-oxygen process. It is therefore suggestion to use much more basic electrodes than rutile for steel welding.

Originality/value: Proposal of welding methods in terms of oxygen content in welds was given 12 years ago, however still it is not very popular. New researches and results could prove that it is very important and original proposal.

\section{References}

Sylvain St-Laurent and Gilles L'Esperance.: Effects of Chemistry and size distribution of inclusions on the nucleation of acicular ferrite of C-Mn steel shielded-metal-arcwelding weldments, IIW Doc II-A-900-93, 1993

Węgrzyn T., Mirosławski J., Silva A., Pinto D., Miros M.: Oxide inclusions in steel welds of car body. Materials Science Forum 2010, vol. 6, pp 585-591

Węgrzyn T., Szopa R., Miros M.: Non-metallic inclusions in the weld metal deposit of shielded electrodes used for welding of low-carbon and low-alloy steel. Welding International, vol. 23, Issue 1, 2009, 54 - 59

Wegrzyn T.: Oxygen and nitrogen in metal weld deposits using arc welding processes. copyright by Publishing House of the Warsaw University of Technology, Warszawa 1999, 1-140

Wegrzyn T.: The Classification of Metal Weld Deposits in Terms of the Amount of Oxygen. Conference of International Society of Offshore and Polar Engineers ISOPE'99, Brest, France 1999, Copyright by International Society of Offshore and Polar Engineers, ISBN 1-880653-43-5, vol. IV Cupertino - California, USA 1999, 212-216 


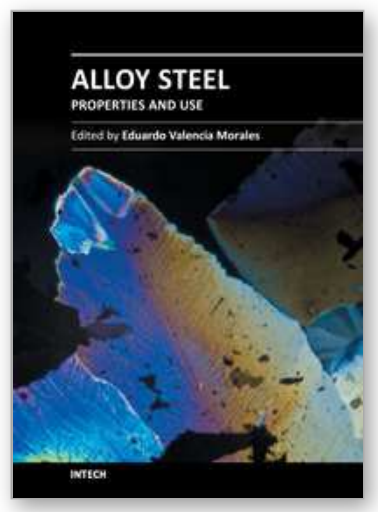

\author{
Alloy Steel - Properties and Use \\ Edited by Dr. Eduardo Valencia Morales
}

ISBN 978-953-307-484-9

Hard cover, 270 pages

Publisher InTech

Published online 22, December, 2011

Published in print edition December, 2011

The sections in this book are devoted to new approaches and usages of stainless steels, the influence of the environments on the behavior of certain classes of steels, new structural concepts to understand some fatigue processes, new insight on strengthening mechanisms, and toughness in microalloyed steels. The kinetics during tempering in low-alloy steels is also discussed through a new set-up that uses a modified Avrami formalism.

\title{
How to reference
}

In order to correctly reference this scholarly work, feel free to copy and paste the following:

Węgrzyn Tomasz (2011). SMAW Process in Terms of the Amount of Oxygen, Alloy Steel - Properties and Use, Dr. Eduardo Valencia Morales (Ed.), ISBN: 978-953-307-484-9, InTech, Available from:

http://www.intechopen.com/books/alloy-steel-properties-and-use/smaw-process-in-terms-of-the-amount-ofoxygen

\section{INTECH}

open science | open minds

\author{
InTech Europe \\ University Campus STeP Ri \\ Slavka Krautzeka 83/A \\ 51000 Rijeka, Croatia \\ Phone: +385 (51) 770447 \\ Fax: +385 (51) 686166 \\ www.intechopen.com
}

\author{
InTech China \\ Unit 405, Office Block, Hotel Equatorial Shanghai \\ No.65, Yan An Road (West), Shanghai, 200040, China \\ 中国上海市延安西路65号上海国际贵都大饭店办公楼 405 单元 \\ Phone: +86-21-62489820 \\ Fax: $+86-21-62489821$
}


(C) 2011 The Author(s). Licensee IntechOpen. This is an open access article distributed under the terms of the Creative Commons Attribution 3.0 License, which permits unrestricted use, distribution, and reproduction in any medium, provided the original work is properly cited. 